\title{
REMOTE SENSING APPROACH TO EVALUATE POST-FIRE VEGETATION STRUCTURE
}

\author{
A.Novo ${ }^{1 *}$, H.González-Jorge ${ }^{2}$, J.Martínez-Sánchez ${ }^{1}$, H:Lorenzo ${ }^{3}$ \\ ${ }^{1}$ Geotech Group, CINTECX, Department of Natural Resources and Environmental Engineering, School of Mining Engineering, \\ University of Vigo, 36310, Vigo, Spain - (annovo, joaquin.martinez)@uvigo.es \\ ${ }^{2}$ Geotech Group, Department of Natural Resources and Environmental Engineering, School of Aerospace Engineering, University of \\ Vigo, 32004, Ourense, Spain - higiniog@uvigo.es \\ ${ }^{3}$ Geotech Group, CINTECX, Department of Natural Resources and Environmental Engineering, School of Forestry Engineering, \\ University of Vigo, 36005, Pontevedra, Spain - hlorenzo@uvigo.es
}

Commission III, WG III/10

KEY WORDS: Forest Fire, Mapping, Remote Sensing, Image Processing, LiDAR data, Point Cloud Processing, Vegetation structure.

\begin{abstract}
:
Spain is included in the top five European countries with the highest number of wildfires. Forest fire can produce significant impacts on the structure and functioning of natural ecosystems. After a forest fire, the evaluation of the damage severity and spatial patterns are important for forest recovery planning, which plays a critical role in the sustainability of the forest ecosystem. The process of forest recovery and the ecological and physiological functions of the burned forest area should be continuously monitored. Remote sensing technologies and in special LiDAR are useful to describe the structure of vegetation. The vegetation modelling and the initial changes of forest plant composition are studied in the forest after mapping the burned areas using Landsat-7 images and Sentinel-2 images. Normalized Burn Ratio (NBR) index and Normalized Difference Vegetation Index (NVVI) is calculated as well as the difference before and after fire. The evaluation of temporal changes of vegetation are analysed by statistical variables of the point cloud, average height, standard deviation and variance. Fraction Canopy Cover (FCC) also is calculated and the point cloud is classified following the fuel model by Prometheus. An analysis method based on satellite images was completed in order to analyse the evolution of vegetation in areas that suffer forest fire.
\end{abstract}

\section{INTRODUCTION}

Nowadays, wildfires constitute an important pressure in forested ecosystems, introducing a high risk of direct damage to humans and structures (Pausas et al. 2009). The analysis performed by the European Forest Fire Information System (EFFIS) indicate an increase in the length of the wildfire season the last 30 years (San-Miguel-Ayanz et al. 2017). Spain is included in the top five European countries with the highest number of wildfires. In 2019, 10.648 forest fire have been registered in Spain, of which $43,23 \%$ happened in the north west of Spain according to data from the Ministry of Agriculture, Fisheries and Food. Galicia is one of the most important forest areas in Europe and in the last year it has been registered 1.676 forest fires in 2019 cover of 13.691 ha (Government of Spain 2019).

Fire is one of the greatest forms of disturbance to terrestrial communities, and plays an important role in composition and structure of forest. As ecosystems recover from fire, changes occur in the composition and structure of vegetation affecting the mass, spatial arrangement and condition of fuels (Gosper, Prober, and Yates 2013). Understanding how ecosystem structure changes with time since fire is therefore critical for identifying appropriate fire return intervals for biodiversity conservation and in predicting the behaviour of fires (Alvarez et al. 2009; Gosper et al. 2012). Recurrent fire in short succession could lead to unfavourable management outcomes including the loss of habitat features of long-unburnt vegetation, decline in carbon stocks and decline in the extent of mature woodland vegetation communities which are distinct in floristic composition (Gosper, Prober, and Yates 2013).

Remote sensing technologies, and in special LiDAR (Light Detection and Ranging) is an active remote sensing technology that can accurately measure three-dimensional vegetation structure. over large areas at a much lower cost than traditional field-based methodologies. The core value of aerial LiDAR lies in its capacity to penetrate the canopy cover down to the underlying ground surface (Hyyppä et al. 2008). Airborne fullwaveform LiDAR data contains large amounts of structural information, and presents a powerful avenue for providing detailed foliage distribution information over large areas. Studies based on LiDAR data have explored the possibilities to use these redundant vegetation reflections to map vertical vegetation structures (Hill et al. 2002; Suárez et al. 2005; Zimble et al. 2003). LiDAR derived canopy height, canopy height variation and canopy cover metrics have been used widely in forest ecological studies to determine or predict a number of important forest attributes, including forest vertical layering and overall architecture (Maltamo et al. 2005), vegetation strata and forest genera (Maltamo et al. 2005) and vegetation regeneration (Maltamo et al. 2005). LiDAR data have been successfully employed to quantify variation and dynamics in vegetation structure (Weishampel et al. 2007; Hantson, Kooistra, and Slim 2012; Korpela et al. 2009).

Corresponding author 
There are free available for Spain high spatial resolution LiDAR point cloud data $\left(0.5\right.$-point measurement per $\left.\mathrm{m}^{2}\right)$ and the derived digital elevation models $(25-50 \mathrm{~cm}$ per pixel). LiDAR data has been available as open data since 2008 in the National Centre for Geographical Information (CNIG 2019).

Understanding community response to fire requires time series spanning these temporal scales (Watson et al. 2012). Contemporary sources documenting fire events, such as satellite images.

Timely and accurate burned area mapping is essential for quantifying the environmental impact of wildfires. Traditionally, moderate to coarse resolution satellite sensors have been used, such as MODIS (Moderate Resolution Imaging Spectrometer (Regos 2018). However, their coarse spatial resolution (pixel size of $500 \mathrm{~m}$ or greater) provides only a rough estimate of the burn perimeter. Burned areas mappings with the detail required can be produced with high-resolution satellite imagery. Landsat data have been predominately used for this purpose (Hawbaker et al. 2017), due to their rich spectral information, specially the shortwave infrared (SWIR) bands important for burned area mapping. Landsat free data provision policy form the United States Geological Survey (USGS) since 2008. The Sentinel-2 mission developed and operated by the European Space Agency (ESA) as part of the Copernicus programme of the European Commission (EC) is providing free of charge high-resolution optical imagery since 2015. The Sentinel-2 data are characterized by high spatial resolution (10$20 \mathrm{~m}$, depending on the band) and high temporal frequency (5 days) front of 16 days of Landsat temporal resolution. There are recent studies have investigated their protentional for burned area mapping (Roteta et al. 2019; Amos, Petropoulos, and Ferentinos 2019).

The present manuscript explores the extent that these two readily available hight-resolution data sources (aerial images and LiDAR) can be exploited to support more efficient vegetation structure mapping and monitoring.

The main of this work is to analyse the potential of PNOALiDAR as a tool for short-term as long-term monitoring of changes in vegetation structure after forest fire. Firstly, the study of area is chosen where LiDAR data are available before and after forest fire. Then, the NDVI and NBR index are calculated for the satellite images and the area of fires are mapped. Finally, the vegetation structure is analysed by Canopy Cover Fraction (CCF) index and vertical composition. In particular, the main contributions of this study are summarized as:

Development an algorithm to automatically calculated NDVI and NBR index for Landasat-7 and Sentinel-2 images.

Design of a methodology to group tree points by height, Prometheus classification and heights established in ASPRS classification.

Determination of vertical and horizontal parameters in structure of vegetation. postfire.

Analysis of vegetation changes prefire and

\section{MATERIAL AND METHODS}

\subsection{Area of study}

The study area is located in the northwest of Spain. It belongs to the Natural Park of Baixa Limia Serra do Xurés, which has been catalogued as an Area for Special Conservation (ASC). The Municipality of Lobios is in the Forest District XV and is catalogued as a high-risk area and classified with a very high potential risk index (Xunta de Galicia 2018). The protected areas are ideal settings for research. The object of this study is an area of $802.60 \mathrm{Ha}$ in the northeast part of the municipally of Lobios (Figure 1). The study area registered forest fires in 2001, 2011 and 2017 (Regos 2018) in which the structural changes of vegetation will be analysed. The climatic type existing in the Baixa Limia is called sub-Mediterranean oceanic temperate, which indicates a certain aridity during the summer, this means a large part of vegetation is adapted of dry periods. Under this climatic type, the potentially dominant vegetation in most of the territory is Quercus pyrenaica and Quercus robur. The main tree species are, Betula alba, Quercus suber, Arbutus unedo, Pinus sp., Ulex sp., Cytisus scoparius and Erica sp. These are several endemic plants, including Portugal laurel and Prunus lusitanica, a species that colonizes the ravines and other areas that have high humidity. The biogeographical location of Baixa Limia greatly favours the diversity of the flora in this territory.

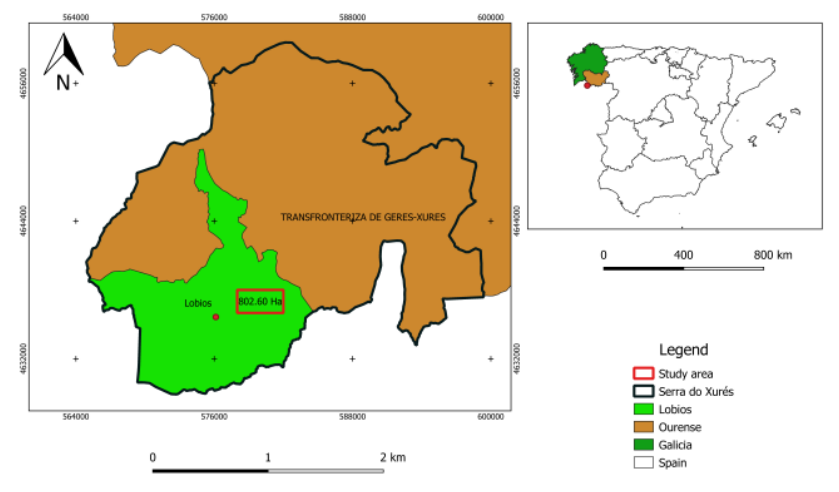

Figure 1. Location of study area.

\subsection{Materials}

Low-density ALS data were provided by the PNOA (National plan of aerial photography) through the IGN (National Geographic Institute) website. The objective of the LiDARPNOA project is to cover the entire Spanish national territory in point clouds with $\mathrm{X}, \mathrm{Y}$ and $\mathrm{Z}$ coordinates obtained by airborne ALS sensors, with a density of 0.5 points per $\mathrm{m}^{2}$ and altimetric accuracy better than $20 \mathrm{~cm}$. The ALS flight was performed in 2009 and in 2016. Data were provided in $2 \mathrm{~km} \times 2 \mathrm{~km}$ tiles of raw data points in a LAZ binary file (compressed LAS file), containing $\mathrm{x}$ and $\mathrm{y}$ coordinates (EPSG:25829 ETRS89/UTM Zone 29N) and ellipsoidal elevation $Z$. The LAZ files were decompressed using the Laszip command from the LAStools software (Isenburg 2012), to obtain the LAS files. Due to the large extension of the study area, the area was divided in two zones and in the first area only it was used the points were in the area affected by forest fire.

In summary, the ALS point clouds were first filtered to generate a surface model (cell size $0.5 \mathrm{~m}$ ), and the data was normalizing by subtracting the DTM from the point cloud. 
In this work it will make use of satellite imagery to mapping the burned areas. Wildfires events after ALS data was in 2011 and in 2016 so it was used Landsat-7 images. Furthermore, in 2017 was registered a wildfire in the area and to mapping was used Sentinel-2 images. The methodology described is the same for both images.

Landsat-7 was launched in 1999 and involving three large American governmental organizations NASA (National Aeronautics and Space Administration), NOAA (National Oceanic and Atmospheric Administration) and USGS (United States Geological Survey). Landsat-7 is equipped with ETM+ (Enhanced Thematic Mapper Plus). A full surface scan by Landsat-7 takes 232 turns or 16 days. Satellite imagery were downloaded from the Landsat Viewer, a remote sensing satellite image tool. Inputs images used for this study were recorder on 10 August of 2011 (pre-fire) and 18 February of 2012 (post fire). Only were considered the band 3 (wavelength 0.63-0.69 $\mu \mathrm{m}$ ) and band 4 (wavelength $0.77-0.90 \mu \mathrm{m}$ ) to calculate NDVI index, and band 7 (wavelength 2.09-2.35 $\mu \mathrm{m}$ ) in combination with band 4 to calculate NBR index. The resolution of bands was $30 \mathrm{~m}$.

The imagery from Sentinel 2 consists of a partnership of twin satellites flying in the same orbit but phased at $180^{\circ}$ to give a revisit frequency of 5 days. These satellites are a mission of the Copernicus program designed by the European Commission in partnership with European Space Agency (ESA). Satellite imagery from the Sentinel 2 mission was used and downloaded from the Copernicus Open Hub. The input images used in this study were selecting pursuing a low cloud percentage from Sentinel-2A satellite and processing level L2A. Images count with geometric and radiometric correction, which facilitates the methodology Two images were recorder on 6 August of 2017 (pre-fire) and 24 December of 2017. They were considered the band 4 (central wavelength $665 \mathrm{~nm}$ ) and band $8 \mathrm{~A}$ (central wavelength $865 \mathrm{~nm}$ ) to calculate NDVI index and band 4, band 6 (wavelength $740 \mathrm{~nm}$ ), band 7 (wavelength $783 \mathrm{~nm}$ ), band 8A and band 12 (central wavelength $2190 \mathrm{~nm}$ ) to calculate NBR index, with a spatial resolution of $20 \mathrm{~m}$.

\subsection{Data processing}

This study was developed using QGIS software (QGIS Development Team 2013) and Python language (Van Rossum 2007) for mapping and spatial analysis. The computer on which the data processing was carried out is an MSI GP72 LEOPARD $\mathrm{PRO}$, with the following technical characteristics:

$$
\begin{aligned}
& \text { Processor: Inter(R) Core (TM) i7 - 7700HQ } \\
& \text { CPU @2.80GHz. } \\
& \text { - } \quad \text { Installed RAM: 16.0 GB. } \\
& \text { - } \quad \text { System type: 64-bit operating system, x64-based } \\
& \quad \text { processor. }
\end{aligned}
$$

Data processing begins detecting fire affected areas. NBR is used to identify burned areas and provide a measure of burn severity (Epting, Verbyla, and Sorbel 2005; Escuin, Navarro, and Fernández 2008). It is calculated as a ratio between the NIR and SWIR2 values in traditional fashion. The NIR band is sensitive to vegetation chlorophyll content, while the SWIR2 band is sensitive to soil and vegetation water content (ELVIDGE 1990) providing information on typical conditions that occur after the fire events. NBR for Landsat 7 images was computed according to the Equation 1.

$$
N B R=\frac{B 4-B 7}{B 4+B 7}
$$

where $\quad$ NBR $=$ Normalized Burn Ratio B4 = band NIR (Near Infrared) B7 = band SWIR-2 (Shortwave Infrared)

NBR for Sentinel 2 images was computed according the equation 2. The BAIS2 spectral index for burned area mapping was specifically designed to take advantage of the Sentinel 2 MSI spectral characteristics. The equation 2 present benefits from vegetation properties described in the red-edge spectral domains and the radiometric response in the SWIR spectral domain, largely recognized to be efficient in the determination of burned areas (ELVIDGE 1990).

$$
B A I S 2=\left(1-\sqrt{\frac{B 06 * B 07 * B 8 A}{B 4}}\right) *\left(\frac{B 12-B 8 A}{\sqrt{B 12+B 8 A}}+1\right)
$$

where $\quad$ BAIS2 $=$ Index for burned area mapping B06 = band NIR (Near Infrared)

B07 $=$ band NIR (Near Infrared $)$

B8A = band NIR (Near Infrared)

B4 = band RED

B12 = band SWIR (Shortwave Infrared)

Pre-fire, healthy vegetation has very high near-infrared reflectance and low reflectance in the shortwave infrared portion of the spectrum. Recently burned areas on the other hand have relatively low reflectance in the near-infrared and high reflectance in the shortwave infrared band. The burned area shows low values for NBR and BAIS2 indexes while healthy vegetation shows high values for NBR and BAIS2 indexes (Figure 2).

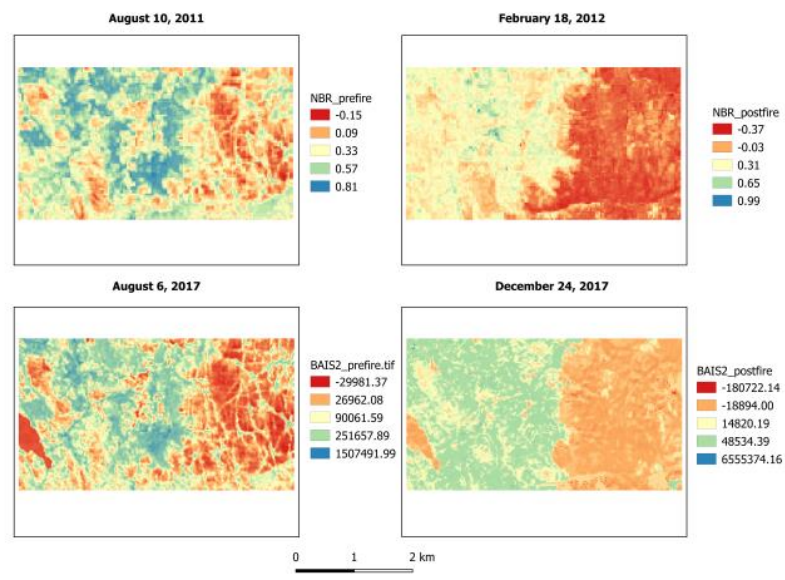

Figure 2. NBR and BAIS2 indexes pre-fire and post-ire situations.

In a following step, the NBR difference (dNBR) between the pre-fire image and post-fire image, which gives an idea of the severity of the calcination is calculated by Equation 3 .

$$
D N B R=N B R_{\text {prefire }}-N B R_{\text {postfire }}
$$


Figure 3 shows high values of dNBR which represent a higher severity of fire and dBAIS2, for the difference between BAIS2 prefire and BAIS2 postfire.
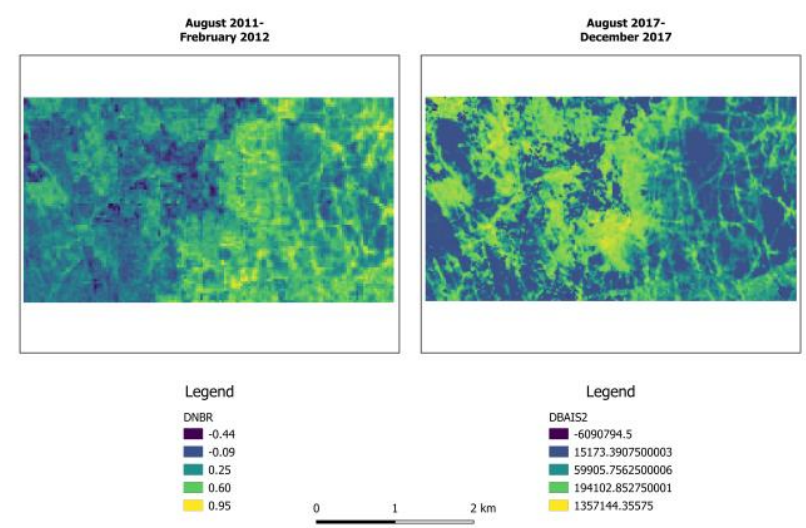

Figure 3. Difference between NBR and BAIS2 indexes.

Once the area burned was mapped, the following step is the calculation of one of the most known and widely used spectral index, NDVI. It takes advantage of green strong vegetation absorption of visible red light, in contrast with its high reflection of near-infrared light. The damage to vegetation caused by fires results in a significant decrease of values. NDVI index was produced by Equation 4. In this study, prefire and postfire NDVI were calculated (Figure 4)

$$
N D V I=\frac{N I R-R E D}{N I R-R E D}
$$

where $\quad$ NDVI $=$ Normalized difference vegetation index NIR = band4 (landsat7) and band8A (sentinel2) RED = band3 (landsat7) and band4 (sentinel2)
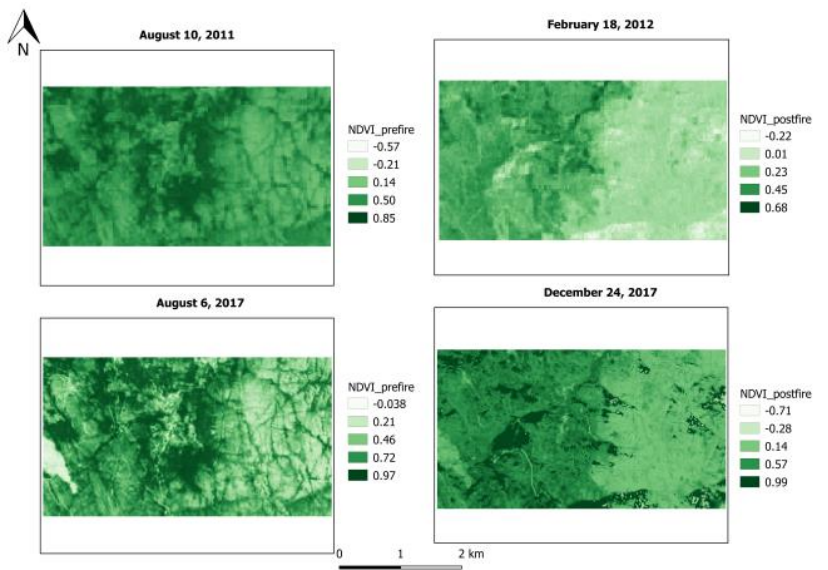

Figura 4. NDVI prefire and postfire in study area

Next stage is the analysis from point clouds, thus ALS data were downloaded from the PNOA. In the case to data processing, two approaches can be considered depending of the synthesized of LiDAR data. The first one consists of derive variables from height distribution functions of the point cloud, while second one consists of synthesize the hight information of LiDAR thought raster layers generation. It has been decided to use the second approach because this process allows a simplification in the volume of data to be processed without significantly affecting the precisions of results. An algorithm was developed in python language to carry on the transformation of $3 \mathrm{D}$ points in $2 \mathrm{D}$ space. The pixel value is related with the $\mathrm{z}$ coordinate form the point cloud.

First phase for the analysis of LiDAR data was the classification of ground points by the DTM of PNOA which is a free product. The point cloud has been grouped in cells of $2 \mathrm{~m}$ of side and the corresponding ground value is known by DTM. A filter was applied to classify the points in two groups, ground points and the rest of points. Next step was the automatic classification of vegetation points and then it carried on the standardized height of points. Last step was the stratification of the vegetation (Figure 4) according to the following height intervals:

Low vegetation: $0.15-0.5 \mathrm{~m}$

Medium vegetation: $0.5-2 \mathrm{~m}$

Medium-Hight vegetation: 2-4 m

Hight vegetation: $>4 \mathrm{~m}$

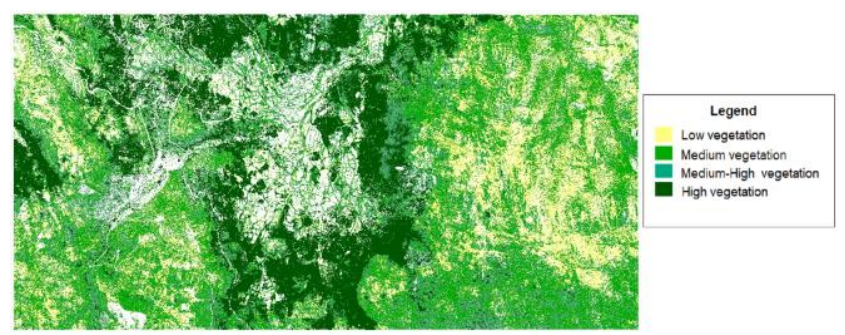

Figure 4. Vegetation stratified by height

Once the vegetation was grouped by heights the statistical variables are calculated by GIS static analysis.

The average height for each established vegetation stratum has been calculated as well as for the entire vegetation. In addition, standard deviation and variance have been calculated. These variables give the characteristics of variability in the vertical structure.

The FCC has been calculated for each stratum of vegetation and also for the entire vegetation. The FCC indicates the proportion of ground covered by vertical projection of each vegetation stratum. Figure 5 shows the binary images of FCC calculated in 2009 and 2016. The area 1 is smaller than area 2, because only was calculated the FCC in the burned area.

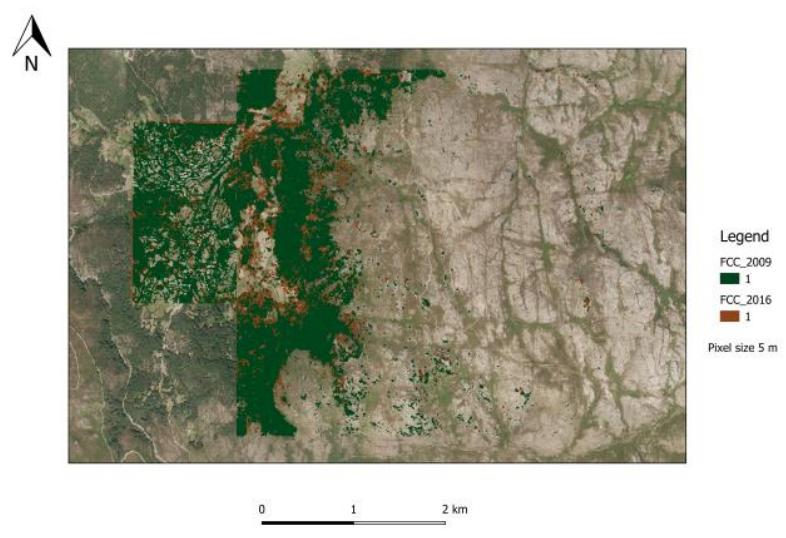

Figure 5. FCC calculated for high vegetation stratum.

The last step was focused in grouping the vegetation into Prometheus classes. In the European environment, a classification of particular interest for its adaptation to regional 
conditions and its suitability for a remote-sensing based production process is that proposed in the European project Prometheus. This classification simplifies and adapts the NFFL (Northern Forest Fire Laboratory) (Albini 1976) system to the characteristics of Mediterranean vegetation. The main classification criterion in Prometheus is the type and height of the propagating element, divided into three well differentiated groups: grass, shrub and tree. The fire is then modelled taking into account the height and density of the propagating elements. Figure 6 show the fuels models according to Prometheus.

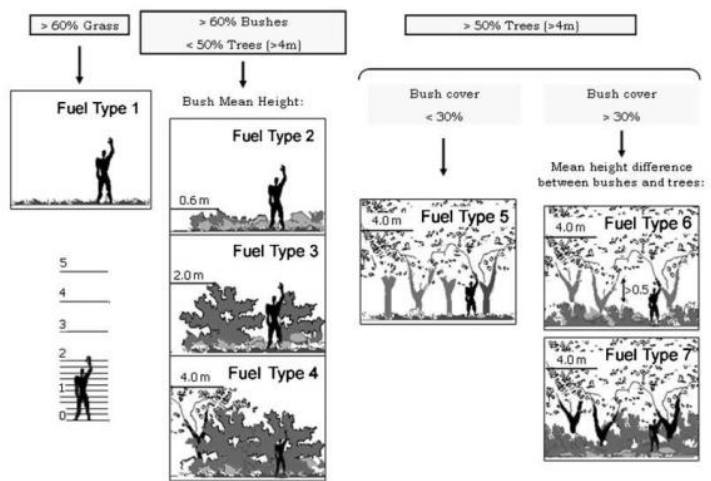

Figure 6. Fuel models by Prometheus (Arroyo et al. 2006).

The information extracted from the LiDAR data corresponds with the number of points in each generated interval also the percentage of vegetation points of the study area have been estimated. Intervals were generated every $0.5 \mathrm{~m}$ to achieve a better characterisation of the fuels on the surface (García et al. 2011). An algorithm developed in python language do the automated process.

The points are grouped in the bands $(0.15-0.3,0.3-0.6,0.6-2,2-4$ and $>4)$. In order to reach optimal classification conditions in the study area, the percentage of points were estimated according to the Equation 5.

$$
\% \text { points }=\frac{T P \text { band }}{\sum \text { Pvegetation }} * 100
$$

$$
\begin{array}{ll}
\text { where } & \text { TP band }=\text { The total points in each stratum } \\
& \sum \text { Pvegetation }=\text { The sum of all points }
\end{array}
$$

Once the percentage of points in each band was calculated the next step was the application of the classification conditions carried out to found out the fuel model. Figure $7 \mathrm{a}$ and Figure $7 \mathrm{~b}$ shows the fuels classified in the study area.

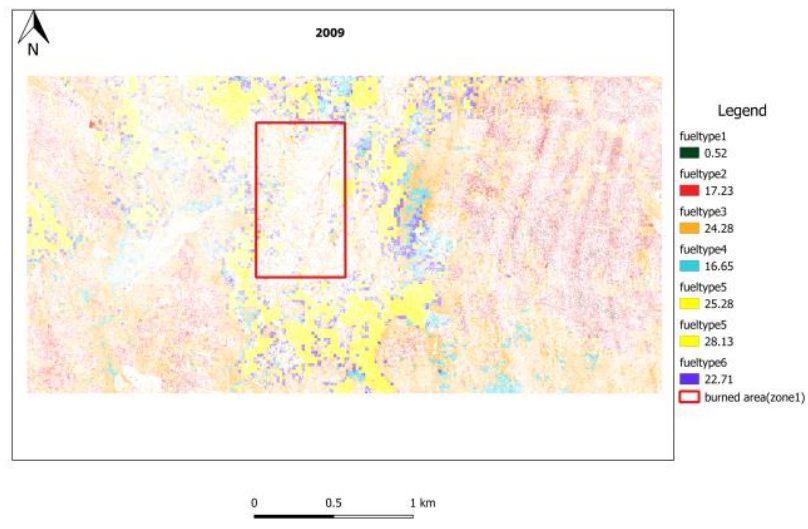

Figure 7a. Fuels classified by Prometheus model in 2009.

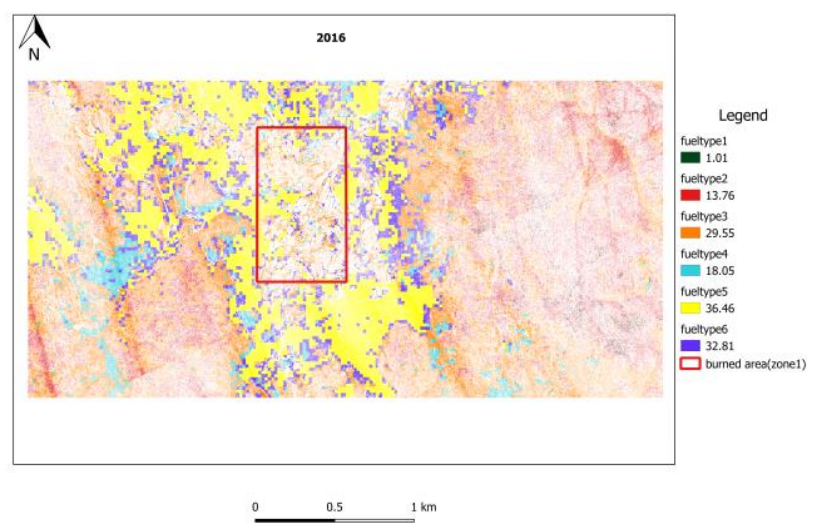

Figure 7b. Fuels classified by Prometheus model in 2016.

\section{RESULTS AND DISCUSSION}

Figure 8 shows the results of the detection of burned area based in the calculation of NBR and BAIS2 indexes. NBR is frequently used to estimate burn severity. Figure 8 shows the results and also show the ground truth used to compare the results previously developed in a mapping burned areas by MODIS sensor between the years 2001 and 2017. (Regos 2018)

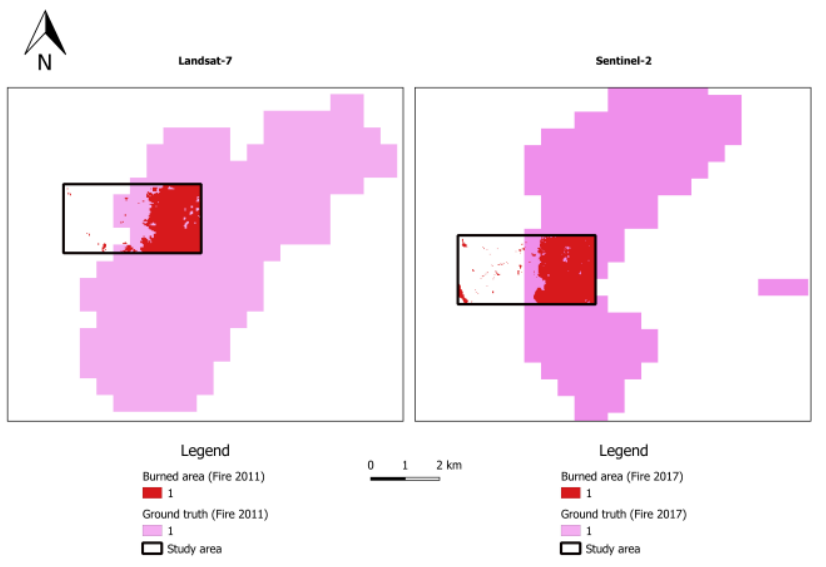

Figure 8. Burned area mapping

The total area burned in 2011 fire detected by imagery of Landasat-7 is $311 \mathrm{Ha}$, in comparison with the $474 \mathrm{Ha}$ of the ground truth used. The total area burned in 2017 fire detected by Sentinel-2 is $335 \mathrm{Ha}$, while that the area of the ground truth used is $411 \mathrm{Ha}$.

Imagery collected before a fire have very high near infrared band values and very low mid infrared band values. Imagery collected over a forest after a fire have very low near infrared band values and very high mid infrared band values. Higher dNBR indicate more severe damage. Areas with negative dNBR values may indicate increased productivity following a fire.

Burn severity levels obtained calculating dNBR proposed by USGS to interpret the burn severity (Figure 9). The results of classification show the area burned in 2011 fire present more high severity than the fire occurred in 2017. The classification algo show the areas unburned that match with the previously unmapped areas. Results shows that fires had low-moderate severity. 


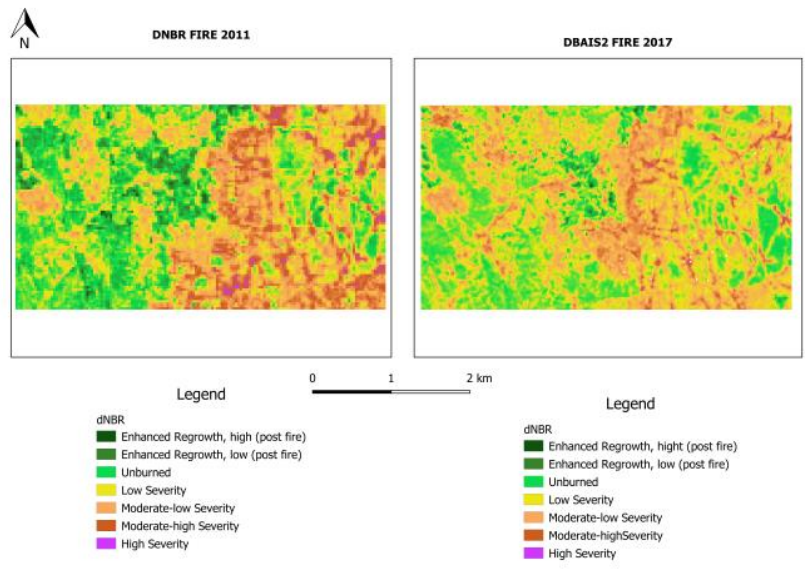

Figure 9. Burn severity levels by dNBR and dBAIS2

NDVI results shows the values near to 0 show rocky areas that can acquire some vegetation up to values close to $0.3 \mathrm{~m}$. From this value presence of vegetation is detected. The higher the value, the more the leafy vegetation will be until reaches values close to 1 . The comparation of NDVI values and the Prometheus classification in Figure 10 show results for the point cloud in 2016 and forest fire in 2017. It is possible to observe how the heights of both data sources matches.

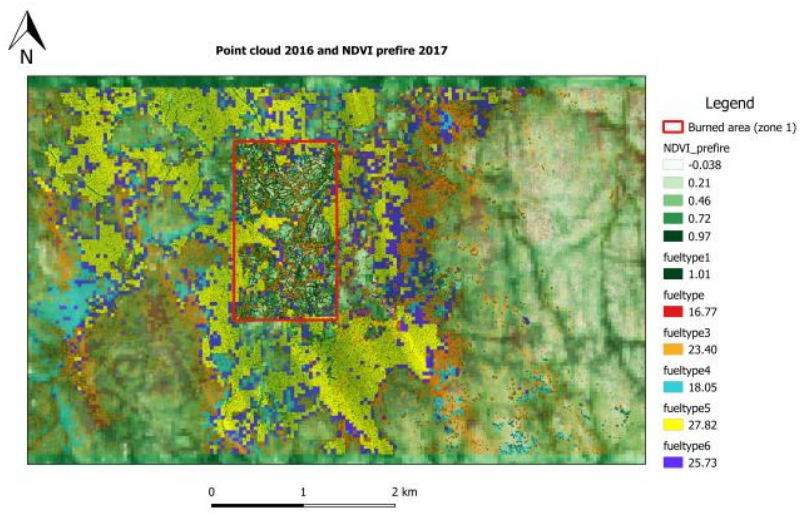

Figure 10. Comparation NDVI and Prometheus classification.

The analysis of Prometheus classification was carried on and Table 1 show the area occupied for each fuel type. It is obviously that study zone 2 contains more pixel because the total area is $400 \mathrm{Ha}$ while the area 1 only is analysed the burned area which represent $55 \mathrm{Ha}$. Fuel type 5 is the most represent in the study area, but in study zone 2 the fuel type 2 has also a considerable representation. On the other hand, fuel type 1 and fuel type 3 are the least represented.

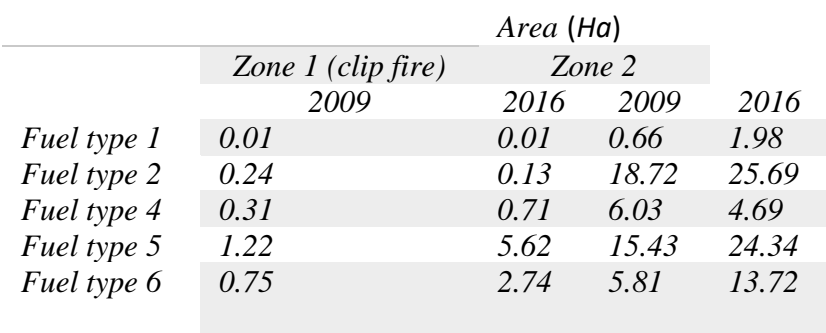

Table 1. Area represent for each fuel type classification.
Results of the average height are show in the Figure 12. The vegetation is divided in 4 classes to calculate the average height, standard deviation, and variance.

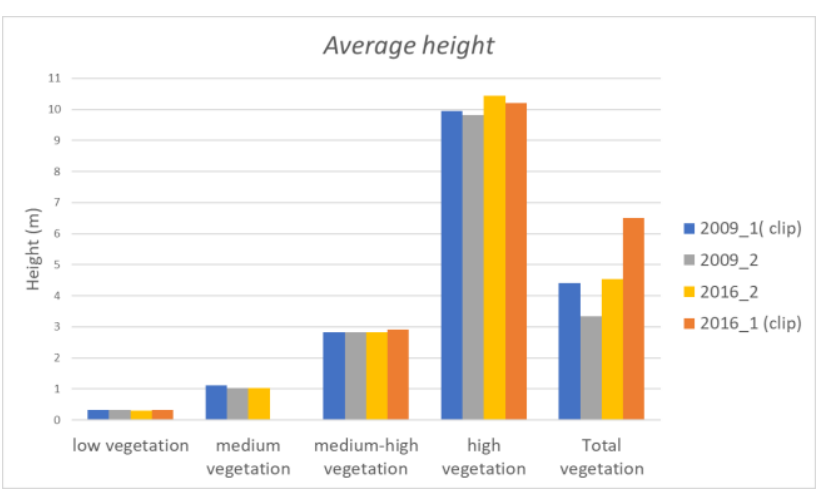

Figure 12. Average variables

In the first vegetation group, low vegetation $(0.15-0.5 \mathrm{~m})$, is unchanged in terms of average height remain in $0.33 \mathrm{~m}$. Respect of medium vegetation $(0.5-2 \mathrm{~m})$ the average height in 2016 is higher in zone $1(1.44 \mathrm{~m})$ respect to zone $2(1.03 \mathrm{~m})$ but show similar values in both years. In the group of medium-high vegetation (2-4 $\mathrm{m})$, the average height is similar in both years showing $2.3 \mathrm{~m}$. In the last vegetation group, high vegetation $(>4 \mathrm{~m})$, in zone 1 an increment of the average height is visualized in 2016, but it is minor than $1 \mathrm{~m}$. The whole vegetation shows higher height in zone 1 in 2009 respect to zone 2, and a significant increase in 2016, being higher in zone 2.

Figure 13 show the results obtained for standard deviation of data. There are not greater variations in each stratum the degree of dispersion is greater in zone 1 in both years and there is more dispersion of data in 2009 .

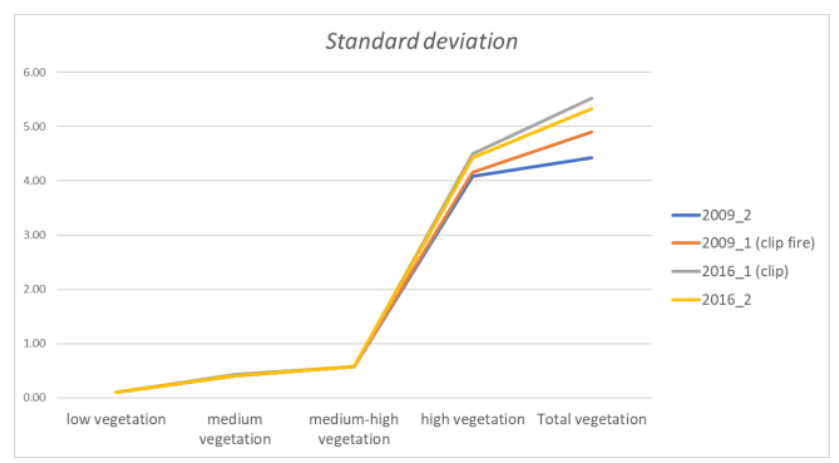

Figure 13. Standard deviation

Figure 14 show the results of FCC obtained for each stratum. In the group of low vegetation is appreciable the increment of FCC in study zone 1 , which represents an increment of $18 \%$ from 2009 to 2016, and an increment too of $15 \%$ in study zone 2 . In medium vegetation stratum both areas suffer an increment of FCC and medium-high vegetation present a similar situation. While high vegetation stratum shows a higher increment of FCC in zone 1 of $20 \%$, while zone 2 almost unchanged. 


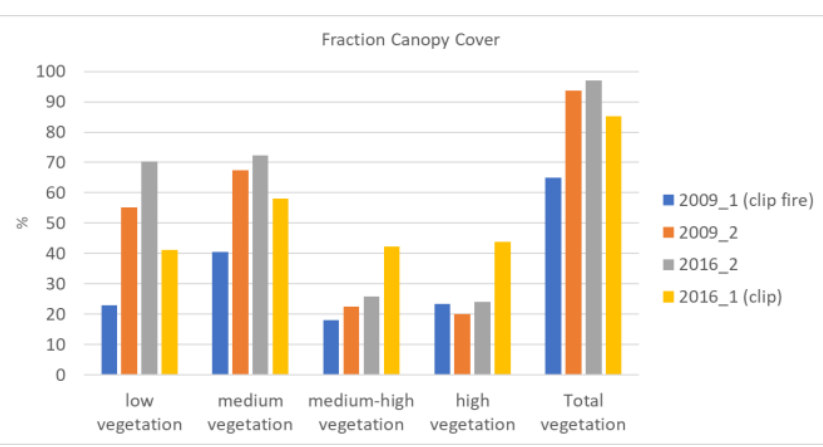

Figure 14. Fraction canopy cover

\section{CONCLUSIONS}

The difference obtains with respect of the ground truth in base of mapping burned area is based on the different resolution of MODIS sensor layer of $500 \mathrm{~m}$, compared with the Landsat-7 resolution of $30 \mathrm{~m}$ and Sentinel-2 resolution of $20 \mathrm{~m}$, which allow mapping burned areas with greater accuracy. It is possible to affirm that the automatically methodology used to map burned areas could provide good results, but would be interested compared the results with fieldwork history.

Burn severity data and maps can aid in developing emergency rehabilitation and vegetation restoration postfire. They can be used to estimate not only the soil burn severity but the likelihood of future downstream impacts due to flooding landslides and soil erosion. Future works could be developed during the next growing season and NBR datasets are often calculated again to assess vegetation survival and delayed mortality.

Ecological recovery, including forest overstory density, tree regeneration, understory development and accumulation of forest floor biomass will vary across patches of different fire severity. Information on canopy cover is essential for understanding spatial and temporal variability in vegetation biomass.

It has been compared that the classification of point cloud according with Prometheus classification of fuels obtains similar results comparing with the calculation of NDVI index.

Results of statistical analysis of point cloud show the possibility to use PNOA-LiDAR data to characterize changes in the structure of vegetation.

The results of this study have special interest for forest management in particular to know the state of vegetation and they evolution postfire.

\section{ACKNOWLEDGEMENTS}

Authors want to thank TOPACIO project (IN852A 2018/37) for financial support given, including the companies Aeromedia UAV, Extraco Obras e Proxectos, Conexiona Telecom and San2 Sustainable Innovation.

\section{REFERENCES}

Albini, Frank A. 1976. Estimating Wildfire Behavior and Effects. Vol. 30. Department of Agriculture, Forest Service, Intermountain Forest and Range ....

Alvarez, R, A Munoz, X M Pesqueira, J Garcia-Duro, O Reyes, and M Casal. 2009. "Spatial and Temporal Patterns in
Structure and Diversity of Mediterranean Forest of Quercus Pyrenaica in Relation to Fire." Forest Ecology and Management 257 (7). Elsevier: 1596-1602.

Amos, Craig, George $\mathrm{P}$ Petropoulos, and Konstantinos $\mathrm{P}$ Ferentinos. 2019. "Determining the Use of Sentinel-2A MSI for Wildfire Burning \& Severity Detection." International Journal of Remote Sensing 40 (3). Taylor \& Francis: 905-930.

Arroyo, Lara A, Sean P Healey, Warren B Cohen, David Cocero, and José A Manzanera. 2006. "Using Object-oriented Classification and High-resolution Imagery to Map Fuel Types in a Mediterranean Region." Journal of Geophysical Research: Biogeosciences 111 (G4). Wiley Online Library.

CNIG. 2019. "Centro Nacional de Información Geográfica."

ELVIDGE, CHRISTOPHER D. 1990. "Visible and near Infrared Reflectance Characteristics of Dry Plant Materials." International Journal of Remote Sensing 11 (10). Taylor \& Francis: 1775-1795. doi:10.1080/01431169008955129.

Epting, Justin, David Verbyla, and Brian Sorbel. 2005. "Evaluation of Remotely Sensed Indices for Assessing Burn Severity in Interior Alaska Using Landsat TM and ETM+." Remote Sensing of Environment 96 (3): 328339. doi:https://doi.org/10.1016/j.rse.2005.03.002.

Escuin, S, R Navarro, and P Fernández. 2008. "Fire Severity Assessment by Using NBR (Normalized Burn Ratio) and NDVI (Normalized Difference Vegetation Index) Derived from LANDSAT TM/ETM Images." International Journal of Remote Sensing 29 (4). Taylor \& Francis: 1053-1073. doi:10.1080/01431160701281072.

García, Mariano, David Riaño, Emilio Chuvieco, Javier Salas, and F Mark Danson. 2011. "Multispectral and LiDAR Data Fusion for Fuel Type Mapping Using Support Vector Machine and Decision Rules." Remote Sensing of Environment 115 (6). Elsevier: 1369-1379.

Gosper, Carl R, Suzanne M Prober, and Colin J Yates. 2013. "Multi-Century Changes in Vegetation Structure and Fuel Availability in Fire-Sensitive Eucalypt Woodlands." Forest Ecology and Management 310. Elsevier: 102109.

Gosper, Carl R, Colin J Yates, Suzanne M Prober, and Blair C Parsons. 2012. "Contrasting Changes in Vegetation Structure and Diversity with Time since Fire in Two Australian Mediterranean-climate Plant Communities." Austral Ecology 37 (2). Wiley Online Library: 164-174.

Government of Spain. 2019. "Ministerio de Agricultura, Pesca y Educacion."

Hantson, Wouter, Lammert Kooistra, and Pieter A Slim. 2012. "Mapping Invasive Woody Species in Coastal Dunes in the N Etherlands: A Remote Sensing Approach Using LIDAR and High-resolution Aerial Photographs." Applied Vegetation Science 15 (4). Wiley Online Library: 536-547.

Hawbaker, Todd J, Melanie K Vanderhoof, Yen-Ju Beal, Joshua D Takacs, Gail L Schmidt, Jeff $\mathrm{T}$ Falgout, Brad Williams, Nicole M Fairaux, Megan K Caldwell, and Joshua J Picotte. 2017. "Mapping Burned Areas Using Dense Time-Series of Landsat Data." Remote Sensing of Environment 198. Elsevier: 504-522.

Hill, R A, G M Smith, R M Fuller, and N Veitch. 2002. "Landscape Modelling Using Integrated Airborne MultiSpectral and Laser Scanning Data." International Journal of Remote Sensing 23 (11). Taylor \& Francis: 23272334.

Hyyppä, J, H Hyyppä, D Leckie, F Gougeon, X Yu, and M Maltamo. 2008. "Review of Methods of Small-footprint 
Airborne Laser Scanning for Extracting Forest Inventory Data in Boreal Forests." International Journal of Remote Sensing 29 (5). Taylor \& Francis: 1339-1366.

Isenburg, Martin. 2012. "LAStools-Efficient Tools for LiDAR Processing." Available at: Http: Http://Www. Cs. Unc. Edu/ Isenburg/Lastools/[Accessed October 9, 2012].

Korpela, Ilkka, Markku Koskinen, Harri Vasander, Markus Holopainen, and Kari Minkkinen. 2009. "Airborne Small-Footprint Discrete-Return LiDAR Data in the Assessment of Boreal Mire Surface Patterns, Vegetation, and Habitats." Forest Ecology and Management 258 (7). Elsevier: 1549-1566.

Maltamo, M, P Packalén, X Yu, K Eerikäinen, J Hyyppä, and J Pitkänen. 2005. "Identifying and Quantifying Structural Characteristics of Heterogeneous Boreal Forests Using Laser Scanner Data." Forest Ecology and Management 216 (1-3). Elsevier: 41-50.

Pausas, Juli G, Joan Llovet, Anselm Rodrigo, and Ramon Vallejo. 2009. "Are Wildfires a Disaster in the Mediterranean Basin?-A Review." International Journal of Wildland Fire 17 (6). CSIRO: 713-723.

QGIS Development Team. 2013. "QGIS Geographic Information System. Open Source Geospatial Foundation Project." http://qgis.osgeo.org.

Regos, Adrián. 2018. "Cartografía de Áreas Queimadas En Galicia No Século XXI: Presentación Do Produto e Aplicación Web Mapping." NACC. Bioloxia 25. Universidade de Santiago de Compostela, Servicio de Publicaciones: 45-53.

Roteta, E, A Bastarrika, M Padilla, T Storm, and E Chuvieco. 2019. "Development of a Sentinel-2 Burned Area Algorithm: Generation of a Small Fire Database for SubSaharan Africa." Remote Sensing of Environment 222. Elsevier: $1-17$.

San-Miguel-Ayanz, J, T Durrant, R Boca, G Libertà, A Branco, D de Rigo, D Ferrari, P Maianti, T A Vivancos, and E Schulte. 2017. "Forest Fires in Europe, Middle East and North Africa." Publications Office.

Suárez, Juan C, Carlos Ontiveros, Steve Smith, and Stewart Snape. 2005. "Use of Airborne LiDAR and Aerial Photography in the Estimation of Individual Tree Heights in Forestry." Computers \& Geosciences 31 (2). Elsevier: 253-262.

Van Rossum, Guido. 2007. "Python Programming Language." In USENIX Annual Technical Conference, 41:36.

Watson, Simon J, Rick S Taylor, Dale G Nimmo, Luke T Kelly, Angie Haslem, Michael F Clarke, and Andrew F Bennett. 2012. "Effects of Time since Fire on Birds: How Informative Are Generalized Fire Response Curves for Conservation Management?" Ecological Applications 22 (2). Wiley Online Library: 685-696.

Weishampel, John F, Jason B Drake, Amanda Cooper, J Bryan Blair, and Michelle Hofton. 2007. "Forest Canopy Recovery from the 1938 Hurricane and Subsequent Salvage Damage Measured with Airborne LiDAR." Remote Sensing of Environment 109 (2). Elsevier: 142 153.

Xunta de Galicia. 2018. "Distritos Forestales." Distritos Forestales. http://mediorural.xunta.gal/es/areas/forestal/ordenacion/d istritos/.

Zimble, Daniel A, David L Evans, George C Carlson, Robert C Parker, Stephen C Grado, and Patrick D Gerard. 2003. "Characterizing Vertical Forest Structure Using SmallFootprint Airborne LiDAR." Remote Sensing of Environment 87 (2-3). Elsevier: 171-182. 